\title{
Alkyl-benzotriazole derivatives as inhibitors of iron and copper corrosion
}

\author{
G. Trabanelli, ${ }^{\dagger}$ A. Frignani,* C. Monticelli and F. Zucchi \\ Corrosion Study Centre “A. Daccò”, University of Ferrara, via A. Saragat 1, \\ 44122 Ferrara, Italy. E-mail: a.frignani@unife.it
}

\begin{abstract}
5-Alkyl derivatives of benzotriazole (1-12 carbon atom long alkyl chain) were tested as inhibitors of pure iron corrosion in sulphuric or hydrochloric acid at $25^{\circ} \mathrm{C}$ and pure copper corrosion in acidic sulphate and saline solutions at $30^{\circ} \mathrm{C}$. This series of compounds was more efficient in contrasting copper than iron corrosion and, generally, the longer the alkyl chain the higher the inhibiting performances and the longer the persistency of the inhibiting action. However, due to a decrease in the solubility, the maximum inhibiting effects were produced by the hexyl derivative. In the case of iron, these compounds were more efficient in the hydrochloric acid solution than in the sulphuric one, while for copper they were more effective in the acidic sulphate solution than in the acidic chloride solution. The higher inhibiting effects for copper can be justified by the mode of BTA adsorption, that consists in chemisorption, instead of physisorption occurring on iron.
\end{abstract}

Keywords: aliphatic chain, benzotriazole, copper, iron.

Received: January 27, 2015.

doi: $10.17675 / 2305-6894-2015-4-1-096-107$

\section{Introduction}

1,2,3-Benzotriazole (BTA) is one of the most effective and widely used organic compounds for corrosion inhibition of copper. The high efficiency of this molecule is commonly attributed to the formation of a polymeric film on copper surface [1-9]. Since BTA can interact also with the iron surface, this molecule also shows interesting properties even towards the corrosion inhibition of iron, e.g. it is effective against acid corrosion [10$16]$ and SCC $[17,18]$.

It has been widely demonstrated that the inhibiting performances of a molecule can be markedly improved by the introduction of proper substituents or groups, or/and by modifying its structure [19-22]. So, the presence of a long aliphatic chain in organic molecules can lead to a marked reduction in metallic corrosion [23, 24]. In this regard, a long alkyl chain in either acetylenic alcohols or in silane compounds was found to produce positive effects in favouring respectively the inhibition of iron acid corrosion [25] or the development of protective coatings. on aluminium [26] or copper [27]. Good results were also obtained when the hydrogen atom in position 5 of the aromatic ring of benzotriazole was substituted by a methyl or a short alkyl chain. Therefore, in our laboratory further investigations were carried out on a series of 5-alkyl-derivatives of BTA as inhibitors of 
iron acid corrosion [28] and copper corrosion [29,30]. This paper shows the improved inhibiting properties of BTA molecule achieved when an aliphatic chain is introduced in the position 5 of the aromatic moiety.

In the case of pure copper the experiments were carried out in $0.1 \mathrm{M} \mathrm{Na}_{2} \mathrm{SO}_{4}$ and $0.1 \mathrm{M} \mathrm{NaCl}$ solutions (at $30^{\circ} \mathrm{C}$ ), acidified to $\mathrm{pH} 2.5$ and in the case of pure iron the tests were carried out in nitrogen-purged $0.5 \mathrm{M} \mathrm{H}_{2} \mathrm{SO}_{4}$ and $1 \mathrm{M} \mathrm{HCl}$ solutions at $25^{\circ} \mathrm{C}$.

In general, the inhibitor concentration adopted was close to the solubility limit of the most efficient homologue.

\section{Experimental}

The substances tested were benzotriazole (BTA) and its methyl (C1), butyl (C4), hexyl (C6), octyl (C8) and dodecyl (C12) derivatives. All of them (but BTA and C1, which were Aldrich products) were synthesized and purified in the laboratory of the Organic Chemistry Group of the Chemistry Department.

Annealed $\left(14 \mathrm{~h}\right.$ at $700^{\circ} \mathrm{C}$ under Argon atmosphere) Armco iron was used to prepare cylindrical electrodes, which exposed a surface area of $3 \mathrm{~cm}^{2}$ to the aggressive solutions. The specimens were prepared by emery paper grindings (from n.150 to n.600) and finally were degreased with acetone. $0.5 \mathrm{M} \mathrm{H}_{2} \mathrm{SO}_{4}$ and $1 \mathrm{M} \mathrm{HCl}$ solutions were the aggressive media, which were deaerated by $\mathrm{N}_{2}$ bubbling before and during the test. The test temperature was $25 \pm 0.1^{\circ} \mathrm{C}$.

Flat OFHC copper electrodes (exposed surface area of $2 \mathrm{~cm}^{2}$ ) were polished with emery papers up to 600 grade, degreased with acetone, rinsed with double distilled water and immediately tested. Copper electrodes were exposed to $0.1 \mathrm{M} \mathrm{Na}_{2} \mathrm{SO}_{4}$ and $0.1 \mathrm{M} \mathrm{NaCl}$ solutions, acidified to $\mathrm{pH} 2.5$ and in equilibrium with the atmosphere at a temperature of $30{ }^{\circ} \mathrm{C}$.

Cathodic and anodic potentiodynamic polarization curves were recorded on independent specimens at $1 \mathrm{mV} \mathrm{s}^{-1}$ scanning rate, starting from the free corrosion potential $\left(E_{\mathrm{CORR}}\right)$. Full details of the experimental part can be found in [28] for iron and [29, 30] for copper.

\section{Results}

\section{1) Iron}

In the sulphuric acid solution the efficiency of this class of substances was not particularly relevant. At $1 \times 10^{-3} \mathrm{M}$ concentration, BTA and $\mathrm{C} 1$ retarded only the cathodic reaction at a limited extent, while a more significant inhibition was achieved by $0.5 \times 10^{-3} \mathrm{M} \mathrm{C} 4$ and chiefly C6 (Figure 1). Only the last derivative succeeded in slightly inhibiting the anodic reaction, although this occurred within a restricted potential interval. The corresponding \%I.E. values, obtained by the extrapolation of the cathodic Tafel lines to the corrosion potential, are collected in Table 1 . Such values increased from 36 for the base 
molecule to 80 for the hexyl derivative, but decreased to 68 in the case of the octyl derivative and became negligible in the case of $\mathrm{C} 12$.

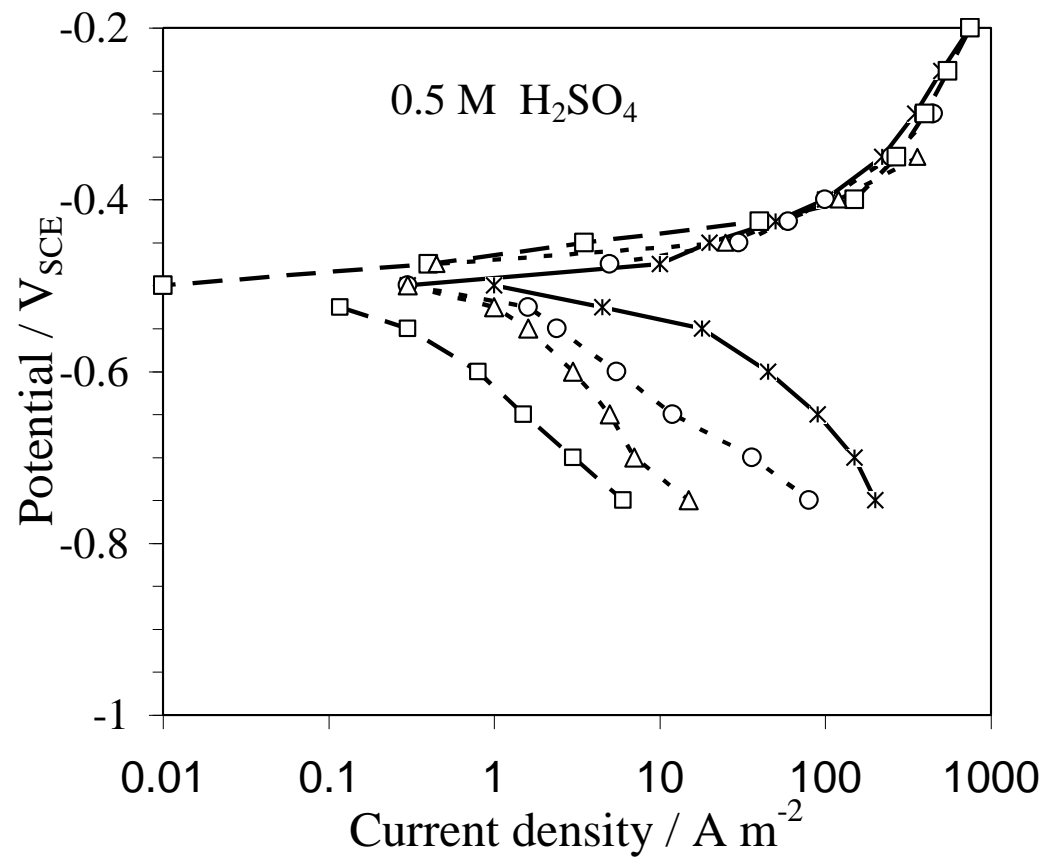

Figure 1. Polarization curves of Armco iron in $0.5 \mathrm{M} \mathrm{H}_{2} \mathrm{SO}_{4}$ (solid line with stars) and in the presence of $1 \mathrm{mM} \mathrm{BTA} \mathrm{(open} \mathrm{circles),} 0.5 \mathrm{mM} \mathrm{C4}$ (open triangles) or C6 (open squares), after $1 \mathrm{~h}$ immersion.

Table 1. Comparison of the \%I.E. values of the various derivatives by the extrapolation of the cathodic polarization curves to the corrosion potential in the two acid solutions.

\begin{tabular}{ccc}
\hline \multirow{2}{*}{ ADDITIVE } & \multicolumn{2}{c}{ \%IE } \\
\cline { 2 - 3 } & $\mathbf{H}_{\mathbf{2}} \mathbf{S O}_{\mathbf{4}}$ & HCl \\
\hline BTA & 36 & 69 \\
$\mathrm{C} 1$ & 33 & 75 \\
$\mathrm{C} 4$ & 60 & 93 \\
$\mathrm{C} 6$ & 80 & 95 \\
$\mathrm{C} 8$ & 68 & 96 \\
$\mathrm{C} 12$ & - & 50 \\
\hline
\end{tabular}

In hydrochloric solution, both the cathodic and anodic processes resulted inhibited (Figure 2). For instance, BTA and $\mathrm{C} 1$ diminished the cathodic polarization currents by around five-fold, $\mathrm{C} 4$ decreased them by about one order of magnitude, while C6 and C8 induced a current reduction by about two orders of magnitude. Both compounds produced 
a concurrent increase in the cathodic Tafel slope $(\beta \mathrm{c})$ value from around 120 to $180 \mathrm{mV} / \mathrm{dec}$; this $\beta c$ variation was almost instantaneous, since it was observed after only 30 min of immersion. Finally, it must be underlined that C12 (saturated solution, around $0.1 \times 10^{-3} \mathrm{M}$ ) exerted about the same action that BTA did.

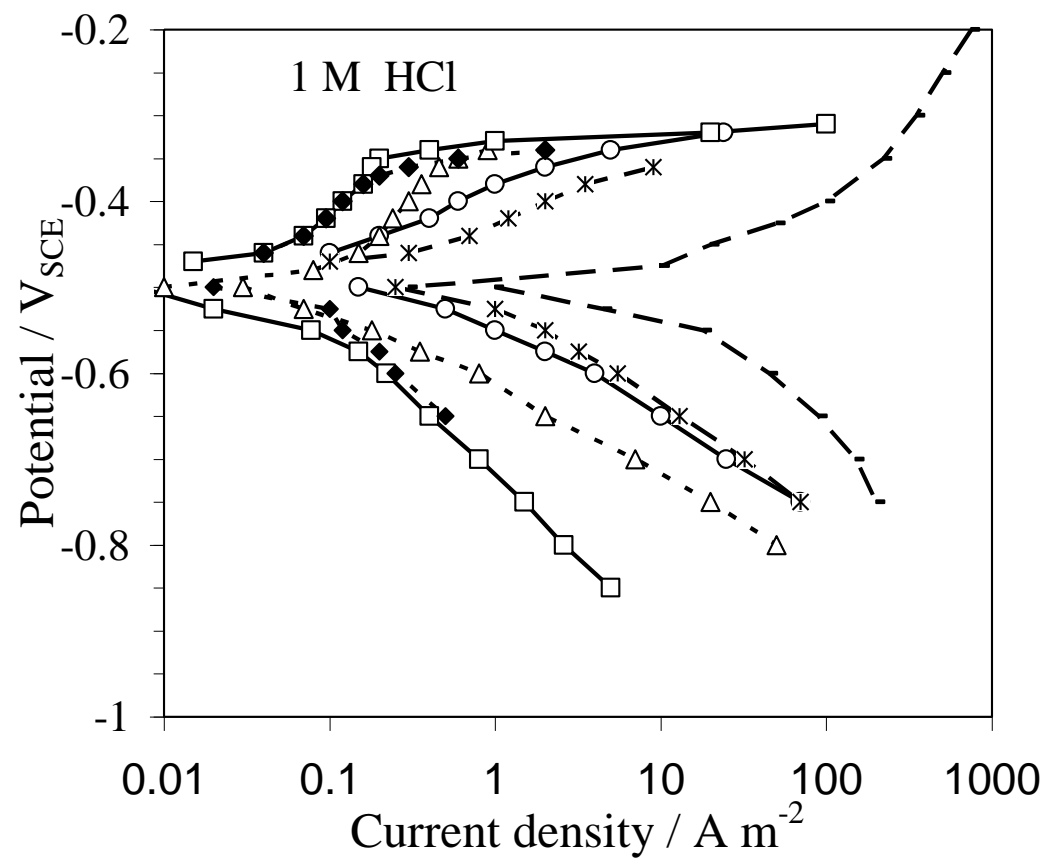

Figure 2. Cathodic and anodic polarization curves of Armco iron in $1 \mathrm{M} \mathrm{HCl}$ in the absence of the inhibitors (dashed line), or in the presence of $0.25 \mathrm{mM}$ additive concentration (C12, $0.1 \mathrm{mM}$ ), at the time of maximum efficiency: open circles, BTA; open triangles, C4; open squares, C6; full diamonds, C8; stars, C12.

In $\mathrm{HCl}$ solution, these substances exerted an inhibition of iron anodic within about $150 \mathrm{mV}$ overvoltage (up to $-380 \mathrm{mV}_{S C E} \mathrm{BTA}$, and up to $-360 /-370 \mathrm{mV}_{S C E}$ the higher homologues) according to the following sequence: $\mathrm{C} 12<\mathrm{BTA}=\mathrm{C} 1<\mathrm{C} 4<\mathrm{C} 6=\mathrm{C} 8$. Besides decreasing the anodic polarization currents, these derivatives augmented the anodic Tafel slope $(\beta$ a). BTA increased $\beta$ a from around 60 to $90 \mathrm{mV} / \mathrm{dec}$, while the higher homologues $(\mathrm{C} 4, \mathrm{C} 6, \mathrm{C} 8)$, which more effectively interfered with the anodic process, induced a more important $\beta a$ rise, up to about $180 \mathrm{mV} / \mathrm{dec}$. At variance with $\beta c$ trend, $\beta a$ increase depended on the immersion time. For instance, just after the electrode immersion in C6 solution, the anodic polarization currents were reduced by about one order of magnitude and $\beta a$ was around $60 \mathrm{mV} / \mathrm{dec}$, like in the blank solution. During the following $8 \mathrm{~h}, \beta a$ augmented slightly, while after $15 \mathrm{~h}$ immersion it underwent an abrupt change up to $165 \mathrm{mV} / \mathrm{dec}$ and the anodic polarization currents decreased further.

The \%I.E. values in the hydrochloric acid solution were markedly higher than those in the sulphuric acid (Table 1). For instance, the higher homologues were characterized by $\%$ I.E. values higher than 90 , except the dodecyl derivative which exhibited a value of 50 . 
The different behavior of these substances in the two acid solutions is clearly presented in Figure 3, where the effects developed by the most efficient compound (C6) in sulphuric and hydrochloric acid solutions are compared. The figure shows that the hydrogen evolution reaction resulted to be hindered by about the same extent in the two acid solutions, while the iron oxidation reaction was by far much more inhibited in the hydrochloric than in the sulphuric acid solution.

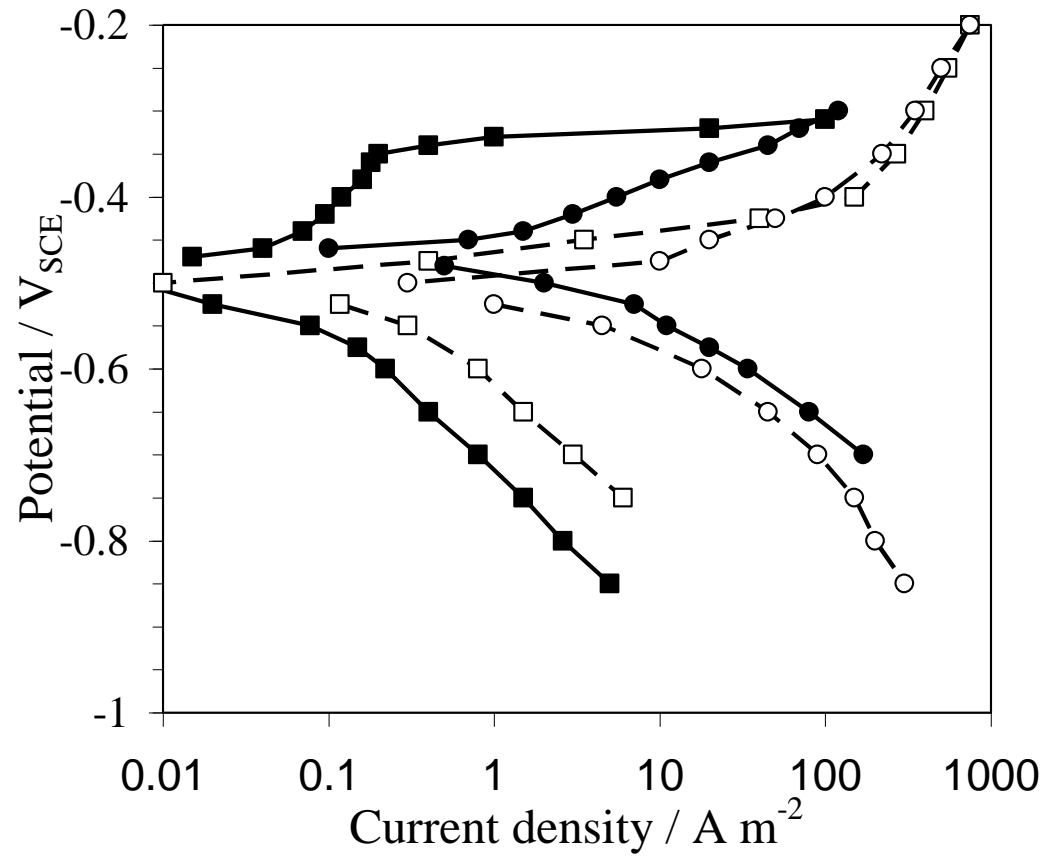

Figure 3. Comparison of the influence of $0.5 \mathrm{mM} \mathrm{C6}$ in $0.5 \mathrm{M} \mathrm{H}_{2} \mathrm{SO}_{4}$ and $0.25 \mathrm{mM}$ C6 in $1 \mathrm{M} \mathrm{HCl}: 0.5 \mathrm{M} \mathrm{H}_{2} \mathrm{SO}_{4}$ in the absence (open circles) and in the presence of $\mathrm{C} 6$ (open squares); $1 \mathrm{M} \mathrm{HCl}$ in the absence (full circles) and in the presence of $\mathrm{C6}$ (full squares).

\section{2) Copper}

In acid sulphate solution, this type of compounds developed an inhibiting action towards copper corrosion at very low concentrations. In regard to the cathodic process, the higher homologues ( $\mathrm{C} 4$ and $\mathrm{C} 6$ ) diminished the polarization currents by around one order of magnitude already at a concentration of $5 \times 10^{-6} \mathrm{M}$, while at $10^{-5} \mathrm{M}$ the cathodic process was inhibited by more than one order of magnitude in the case of the butyl derivative and by about two orders of magnitude by the hexyl derivative. The saturated solution of $\mathrm{C} 8$ induced an effect similar to that afforded by $10^{-5} \mathrm{M} \mathrm{C6}$. At a higher concentration of $10^{-4} \mathrm{M}$, both compounds reduced the cathodic currents by more than two orders of magnitude (Figure 4). The lower homologues (BTA and C1) simply hindered the formation of the cathodic hump ascribed to the presence of adsorbed intermediates formed during $\mathrm{O}_{2}$ reduction $[31,32]$ up to $10^{-4} \mathrm{M}$ concentration. They attained one order of magnitude reduction in the cathodic currents at the higher concentration of $10^{-3} \mathrm{M}$ (Figure 5). 


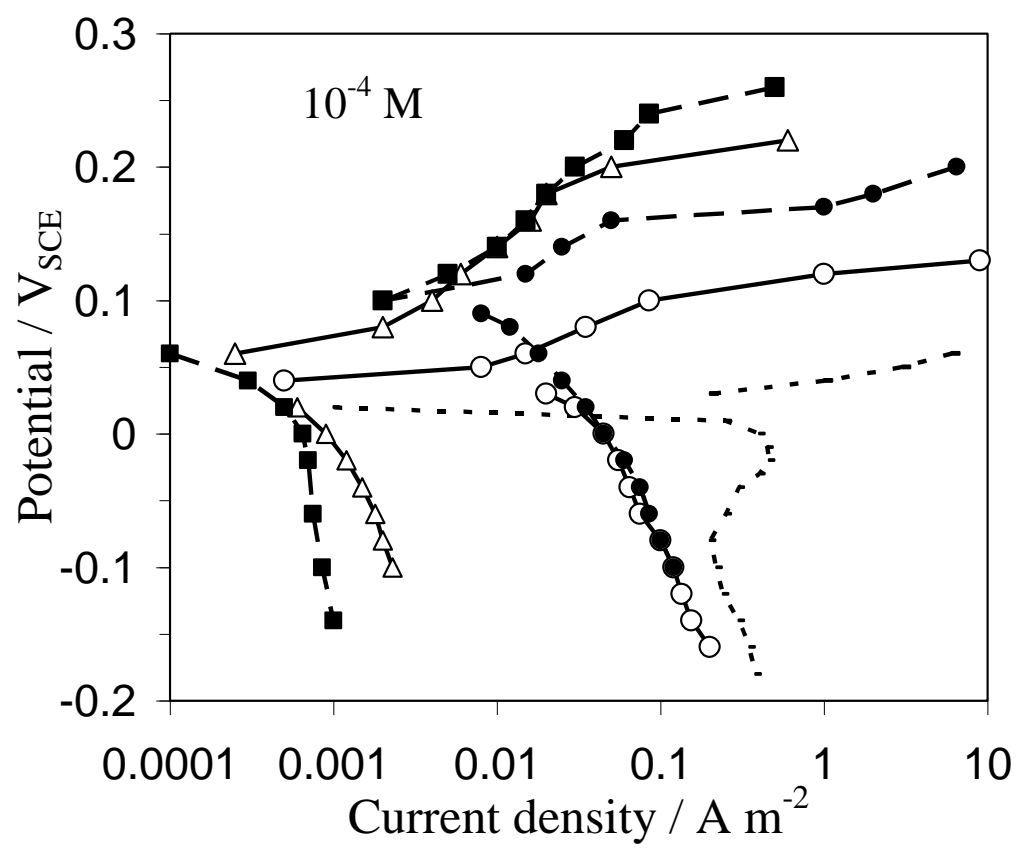

Figure 4. Cathodic and anodic polarization curves of OFHC copper in acidified $0.1 \mathrm{M} \mathrm{Na}_{2} \mathrm{SO}_{4}$ $(\mathrm{pH} 2.5)$ in the absence of inhibitors (dotted line), in presence of $0.1 \mathrm{mM}$ additive concentration (open circles, BTA; full circles $\mathrm{C} 1$; open triangles, $\mathrm{C} 4$; open squares, C6).

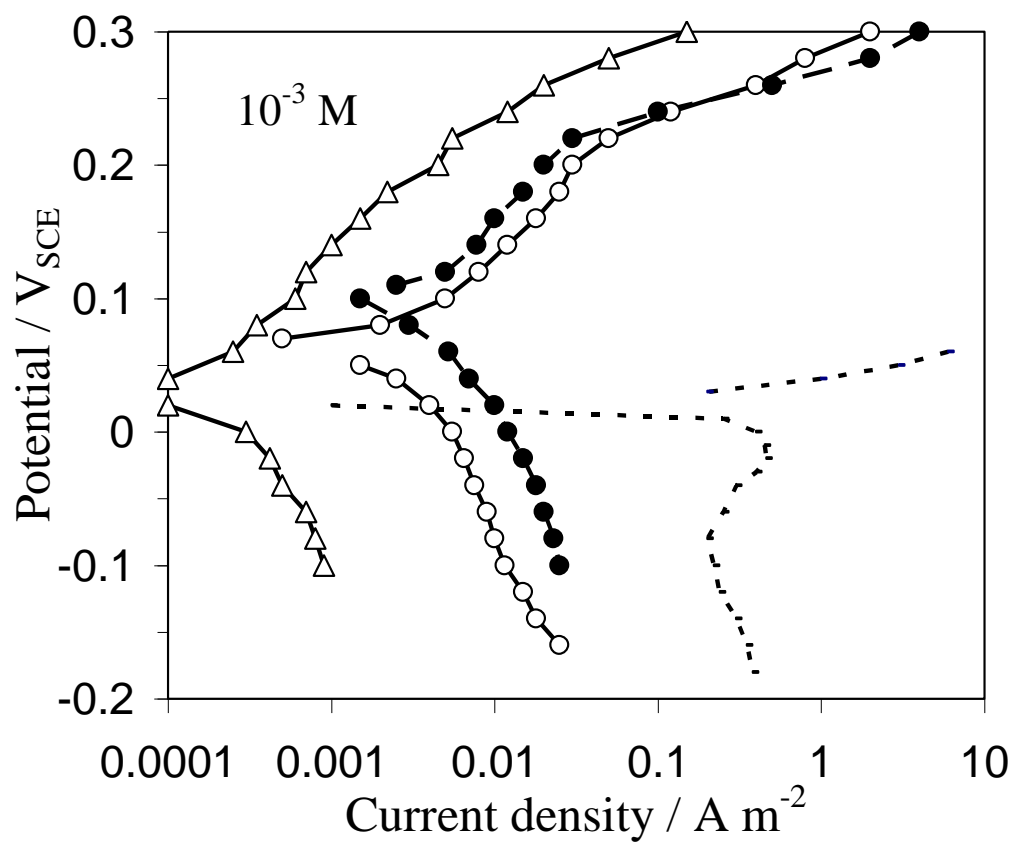

Figure 5. Cathodic and anodic polarization curves of OFHC copper in acidified $0.1 \mathrm{M} \mathrm{Na}_{2} \mathrm{SO}_{4}$ ( $\mathrm{pH}$ 2.5), in the absence of inhibitors (dotted line) and in the presence of $1 \mathrm{mM}$ additive concentration (open circles, BTA; full circles $\mathrm{C} 1$; open triangles, $\mathrm{C} 4$ ). 
The influence exerted on the anodic reaction was more evident. At $10^{-5} \mathrm{M}$ concentration the inhibiting action of BTA and $\mathrm{C} 1$ was limited, but in the presence of $\mathrm{C} 4$ the oxidation reaction of copper resulted to be noticeably hindered with a consequent rise in the anodic curve slope from around 60 to over $120 \mathrm{mV} /$ decade, at least up to a potential (Breakdown Potential, $E_{\mathrm{BR}}$ ) close to $+0.14 \mathrm{~V}_{\mathrm{SCE}}$. Above this potential, the current rapidly increased owing to the onset of localized corrosion attacks over the whole electrode surface. Even C6 and C8 retarded the copper oxidation reaction within a wide potential range, but no inhibiting effects were afforded by the dodecyl derivative owing to the compound insolubility. At $10^{-4} \mathrm{M}$ concentration (Figure 4), BTA and $\mathrm{C} 1$ diminished the anodic polarization currents by respectively about one and two orders of magnitude, notwithstanding their limited influence on the cathodic process. Moreover, both of them presented a clear breakdown potential. The higher homologues $\mathrm{C} 4$ and $\mathrm{C} 6$ reduced further the anodic polarization currents and enlarged the potential range of inhibitor action. However, it must be pointed out that the inhibiting action of $\mathrm{C} 4$ and $\mathrm{C} 6$ was more significant after longer immersion times (e.g. 8 or $24 \mathrm{~h}$ ).

Finally, $10^{-3}$ M BTA (Figure 5) exerted anodic inhibitive effects close to those of $10^{-4} \mathrm{M} \mathrm{C4}$.

The aggressive nature of chloride ions prevented any inhibiting action of BTA and C1 at $10^{-4} \mathrm{M}$ concentration (Table 2). Only the additives with 4 or 6 carbon atom chains highly affected both the anodic and the cathodic reactions: $\mathrm{C} 4$ reduced the cathodic and anodic polarization currents of around one order of magnitude, and C6 of about two orders of magnitude (Figure 6).

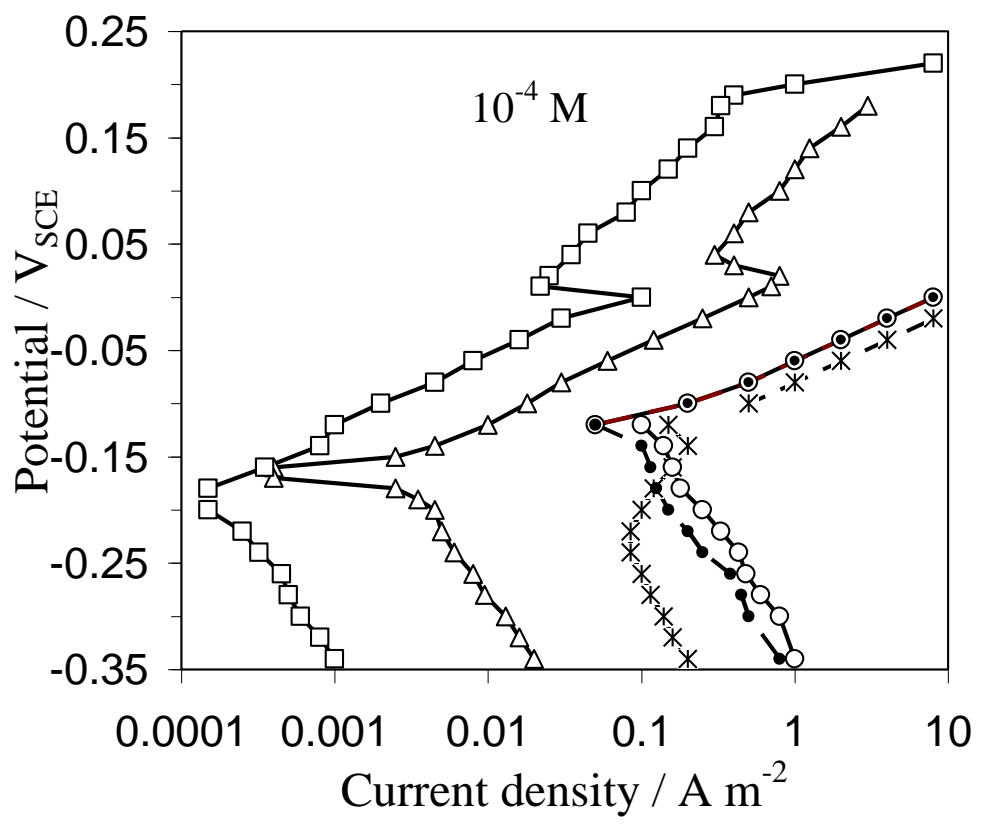

Figure 6. Cathodic and anodic polarization curves of OFHC copper in acidified $0.1 \mathrm{M} \mathrm{NaCl}$ $(\mathrm{pH} 2.5)$, in the absence of inhibitors (dotted line with stars) and in presence of $0.1 \mathrm{mM}$ additive concentration (open circles, BTA; full circles $\mathrm{C} 1$; open triangles, $\mathrm{C} 4$; open squares, C6). 
The comparison (Figure 7) between the polarization curves of $\mathrm{C} 4$ and $\mathrm{C} 6$ in the two acidic media shows that while the influence of these compounds towards the cathodic process in the acidic chloride solution was similar to that shown in the acidic sulphate solution, their influence on the anodic process was lower.

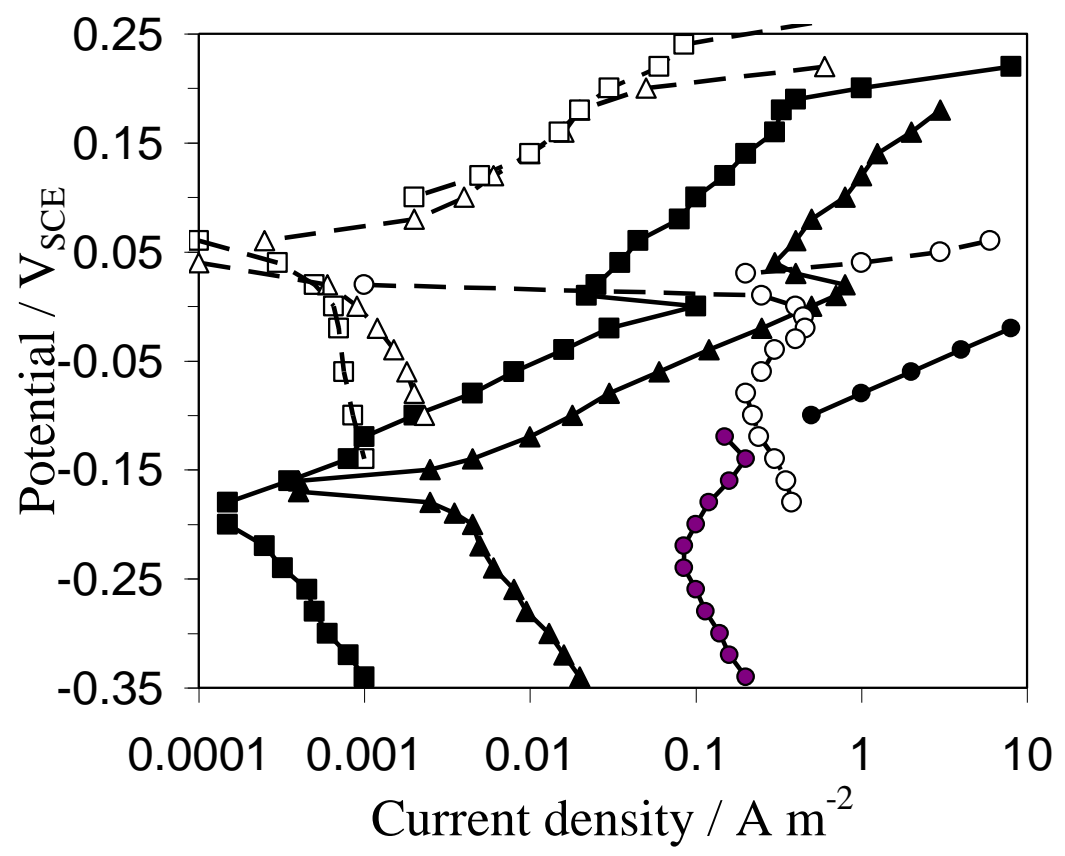

Figure 7. Comparison between the polarization curves of copper in the two uninhibited and $\mathrm{C} 4$ and $\mathrm{C} 6$ inhibited acidic solutions. Open symbols, $0.1 \mathrm{M} \mathrm{Na}_{2} \mathrm{SO}_{4}(\mathrm{pH} 2.5)$; full symbols, $0.1 \mathrm{M} \mathrm{HCl}(\mathrm{pH} 2.5)$; circles, uninhibited solutions, triangles, $\mathrm{C} 4$ inhibited; squares, C6 inhibited.

Table 2. Comparison of the \%I.E. values of the various $0.1 \mathrm{mM}$ derivatives obtained by the extrapolation of the cathodic polarization curves to the corrosion potential in the two acidic solutions. (n.d., not determined).

\begin{tabular}{|c|c|c|}
\hline \multirow{2}{*}{ ADDITIVE } & \multicolumn{2}{|c|}{$\%$ IE } \\
\hline & pH $2.5 \mathrm{Na}_{2} \mathrm{SO}_{4}$ & pH $2.5 \mathrm{NaCl}$ \\
\hline BTA & 92 & $\sim 0$ \\
\hline $\mathrm{C} 1$ & 93 & $\sim 0$ \\
\hline $\mathrm{C} 4$ & 99.5 & 90 \\
\hline C6 & 99.8 & 98 \\
\hline $\mathrm{C} 8$ & 98 & n.d. \\
\hline
\end{tabular}


Table 2 shows that in acidic sulphate solution all the derivatives evidenced noticeably inhibiting effects, much higher than $90 \%$, in dependence of the alkyl chain length. On the contrary, in acidic chloride media, only $\mathrm{C} 4$ and $\mathrm{C} 6$ continued to display a marked, although reduced, tendency to inhibition.

\section{Discussion}

BTA and its derivatives can hinder copper corrosion more efficiently than iron corrosion, because they establish a different type of interaction with the two metal surfaces. In fact, very strong chemisorption occurs on copper and less effective physisorption ensues on iron [33].

In both cases, the presence of a sufficiently long alkyl chain improves the inhibiting action of the base molecule because the van der Waals interactions among the long aliphatic chains can enhance the formation of a thicker, more compact, less defective, more hydrophobic and therefore more protective inhibitor layer [30,34-36]. These positive effects are the greater the longer the chain, at least up to 6 carbon atoms. With longer chain length, the solubility limitations prevail and the inhibiting effects decrease. Moreover, since the maximum effects are observed after a certain time interval, which depends on the chain length, it is likely that the arrangement between the inhibitor molecules through van der Waals interaction of the aliphatic chain needs some time to form [37].

On copper, these substances these substances exert a strong corrosion inhibition at very low concentrations. Very dilute additive solutions (around $10^{-6} \mathrm{M}$ ) affect the oxygen cathodic reduction only, mainly by blocking the surface active centres for the reaction: $\mathrm{Cu}+\mathrm{O}_{2 \text { sol }} \Rightarrow \mathrm{Cu} . \mathrm{O}_{2 \mathrm{ads}}[31,32]$. At higher concentrations $(>10 \mu \mathrm{mole} / \mathrm{L}$ for $\mathrm{C} 6$ and $\mathrm{C} 4$; $>100 \mu \mathrm{mole} / \mathrm{L}$ for $\mathrm{C} 1$ and BTA), the anodic inhibitor effect prevails on the cathodic one, as shown by both the positive shift of $\mathrm{E}_{\mathrm{CORR}}$ and $\mathrm{E}_{\mathrm{BR}}$ values and the increasing anodic curve slope. Under these conditions, a chemisorbed film of triazolic derivatives likely covers the $\mathrm{Cu} / \mathrm{Cu}_{2} \mathrm{O}$ specimen surface and promotes a pseudo-passive behavior of copper. The passive potential range becomes wide at increasing additive concentration in the solution, because it promotes the formation of a more stable and less defective film. However, the chemisorption or the interaction of the inhibiting molecules with the metal surface is likely competitive with the surface interaction of the ions present in solution. For this reason very aggressive anions, such as chlorides, notably reduce the action of the less efficient molecules (BTA and C1), but cannot compete with the chemisorption of the most efficient ones $(\mathrm{C} 4$ or $\mathrm{C} 6)$.

In the case of iron, in sulphuric acid solution these substances hinder chiefly the cathodic hydrogen evolution reaction, while the influence on the anodic process is obtained only in the case of the most efficient compound (C6) and is exerted only in a very narrow potential interval. On the other hand, in hydrochloric acid solution, these additives are more effective and inhibit both the cathodic and the anodic reactions. Such behavior can be justified by physisorption of positively charged protonated $\mathrm{BTAH}^{+}$cations directly on iron surface in sulphuric acid solution and by stronger physisorption of the same cations on 
negatively charged pre-adsorbed chlorides in hydrochloric acid solution [38]. This hypothesis is sustained by the detection of a desorption potential $\left(E_{\mathrm{BR}}\right)$ more or less independent from the homologue type. However, it must be also stressed that, after immersion in inhibited solutions, iron coupons transferred into uninhibited hydrochloric acid solution maintain low corrosion rates for some time [28]. This suggests that, besides physisorption, also chemisorption takes place and contributes to the corrosion protection mechanism.

\section{Conclusions}

- An aliphatic chain of proper length improves the protective performances of benzotriazole molecule towards iron and copper acid corrosion. The maximum effects are observed with a 6 carbon atom chain length, since with longer chains solubility limitations prevail.

- In the case of iron, these BTA derivatives are more efficient in hydrochloric acid, were they inhibit both the anodic and the cathodic reactions, than in sulphuric acid, where they hinder only the cathodic reaction. The type of interaction between the positively charged protonated organic molecules and the metal surface can explain this behavior. In fact, iron surface is negatively charged in hydrochloric acid solution where pre-adsorption of chloride ions occurs. The pre-adsorbed layer synergetically stimulates physisorption of the inhibitor molecules. However, the persistence of a certain protective action when inhibited coupons are immersed in non-inhibited acid solution may indicate that some inhibitor chemisorption can also take place.

- In the case of copper, BTA derivatives act through a strong chemisorption process, so that the inhibiting effects are higher than those on iron corrosion. The interaction of the tested substances with the metal surface should be competitive with the interaction of the ions in the solution, so that very aggressive anions, such as chlorides, notably reduce the action of these molecules, chiefly in the case of the less efficient ones (i.e. those without alkyl chain or with a short one).

\section{References}

1. L. Dugdale and J. B. Cotton, Corros. Sci., 1963, 3, 69.

2. J. B. Cotton and I. R. Scholes, Br. Corros. J., 1967, $2,1$.

3. G. W. Poling, Corros. Sci., 1970, 10, 359.

4. T. Notoya and G. W. Poling, Corrosion, 1976, 32, 216.

5. C. Chadwick and T. Hashemi, Corros. Sci., 1978, 18, 39.

6. B. S. Fang, C. Olson and D. W. Lynch, Surf. Sci., 1986, 176, 476.

7. J. Eickmans, D. Holtkamp, H. J. Rother, R. Holm, A. Benninghoven and T. Gantenfort, Proceedings of 7th European Symp. on Corrosion Inhibitors, Ferrara, Italy, $17^{\text {th }}-21^{\text {st }}$ Sept. 1990, Ann. Univ. Ferrara, Sez V, Suppl. no. 9, 1990, p. 847.

8. D. Tromans and J. C. Silva, Corrosion, 1977, 53, 16.

9. M. Finšgar and I. Milošev, Corros. Sci., 2010, 52, 2737. 
10. B. Sathianandhan, K. Balakrishnan and N. Subramanyan, Br. Corros. J., 1970, 5, 270.

11. R. J. Chin and K. Nobe, J. Electrochem. Soc., 1971, 118, 545.

12. G. Trabanelli, A. Frignani, G. Brunoro, C. Monticelli and F. Zucchi, Mater. Perform., 1985, 24, 33.

13. A. Frignani, C. Monticelli, G. Brunoro, M. Zucchini and I. Hashi Omar, Br. Corros. J., 1987, 22, 103.

14. G. K. Gomma, Mat. Chem. Phys., 1998, 55, 235.

15. A. Bellaouchu, B. Kabkab, A. Guenbour and A. Ben Bachir, Progr. Org. Coat., 2001, 41, 121.

16. S. Tamil Selvi, V. Raman and N. Rajendran, J. Appl. Electrochem., 2003, 33, 1175.

17. D. E. Davies, J. P. Dennison and A. A. Odeh, Proceedings of 6th European Symp. on Corrosion Inhibitors, Ferrara, Italy, $16^{\text {th }}-20^{\text {th }}$ Sept. 1985, Ann. Univ. Ferrara, Sez V, Suppl. no. 8, 1985, p. 669.

18. L. Niu, C. N. Cao, H. C. Lin and G. L. Song, Corros. Sci., 1998, 40, 1109.

19. G. Trabanelli and V.Carassiti, "Mechanism and Phenomenology of Organic Inhibitors", in Advances in Corrosion Science and Technology, Vol. 1, M. G. Fontana and R. W. Staehle Eds., Plenum Press, N.Y., 1970.

20. G. Schmitt, Br. Corros. J., 1984, 19, 165.

21. Y. I. Kuznetsov, Organic Inhibitors of Corrosion of Metals, Plenum Press, N.Y., 1996.

22. Y. I. Kuznetsov, Int. J. Corros. Scale Inhib., 2015, 4, no. 1, 15.

23. N. Huynh, S. E. Bottle, T. Notoya, A. Trueman, B. Hinton and D. P. Schweinsberg, Corros. Sci., 2002, 44, 1257.

24. Z. Szklarska-Smialowska and G. Wieczorek, Corros. Sci., 1971, 11, 843.

25. A. Frignani, C. Monticelli, F. Zucchi and G. Trabanelli, Int. J. Corros. Scale Inhib., 2014, 3, no. 2, 105.

26. A. Frignani, F. Zucchi, G. Trabanelli and V. Grassi, Corros. Sci., 2006, 48, 2258.

27. F. Zucchi, V. Grassi, A. Frignani and G. Trabanelli, Proc. Eurocorr 2003, Budapest (H), 28 Sept-2 Oct. 2003, paper no. 47.

28. A. Frignani, C. Monticelli, F. Zucchi and G. Trabanelli, Proceedings of 10th European Symp. on Corrosion Inhibitors, Ferrara, Italy, $29^{\text {th }}$ Aug-2 ${ }^{\text {nd }}$ Sept. 2005, Ann. Univ. Ferrara, Sez V, Suppl. no. 12, 2005, p. 955.

29. A. Frignani, L. Tommesani, G. Brunoro, C. Monticelli and M. Fogagnolo, Corros. Sci. 1999, 41, 1205.

30. A. Frignani, M. Fonsati, C. Monticelli and G. Brunoro, ibidem, p. 1217.

31. F. Mansfeld, T. Smith and E.P. Parry, Corrosion, 1971, 27, 289.

32. F. Mansfeld and T. Smith, Corrosion, 1973, 29, 105.

33. P. G. Cao, J. L. Yao, J. W. Zheng, R. A. Gu and Z. Q. Tian, Langmuir, 2002, 18, 100.

34. M. D. Porter, T. B. Bright, D. L. Allara and C.E.D. Chidsey, J. Am. Chem. Soc., 1987, 109, 3559.

35. P. E. Laibinis, G. M. Whitesides, D. L. Allara, Y-T. Tao, A. N. Parikh and R. G. Nuzzo, J. Am. Chem. Soc., 1991, 113, 7152. 
36. L. Tommesani, G. Brunoro, A. Frignani, C. Monticelli and M. Dal Colle, Corros. Sci., 1997, 39, 1221.

37. F. Bensebaa, R. Voicu, L. Huron, T. H. Hellis and E. Kruus, Langmuir, 1997, 13, 5335.

38. J. L. Yao, B. Ren, Z. F. Huang, P. G. Cao, R. A. Gu and Z-Q. Tian, Electrochim. Acta, 2003, 48, 1263. 